\title{
Obesity in adults: a clinical practice guideline
}

\author{
Sean Wharton MD, David C.W. Lau MD PhD, Michael Vallis PhD RPsych, Arya M. Sharma MD PhD, \\ Laurent Biertho MD, Denise Campbell-Scherer MD PhD, Kristi Adamo PhD, Angela Alberga PhD, \\ Rhonda Bell PhD, Normand Boulé PhD, Elaine Boyling PhD, Jennifer Brown RD MSc, Betty Calam MD, \\ Carol Clarke RD MHSc, Lindsay Crowshoe MD, Dennis Divalentino MD, Mary Forhan OT PhD, Yoni Freedhoff MD, \\ Michel Gagner MD, Stephen Glazer MD, Cindy Grand MPH, Michael Green MD MPH, Margaret Hahn MD PhD, \\ Raed Hawa MD MSc, Rita Henderson PhD, Dennis Hong MD, Pam Hung MScOT BSc, Ian Janssen PhD, \\ Kristen Jacklin PhD, Carlene Johnson-Stoklossa RD MSc, Amy Kemp BKin BA, Sara Kirk PhD, Jennifer Kuk PhD, \\ Marie-France Langlois MD, Scott Lear PhD, Ashley McInnes PhD, David Macklin MD, Leen Naji MD, \\ Priya Manjoo MD, Marie-Philippe Morin MD, Kara Nerenberg MD MSc, lan Patton PhD, Sue Pedersen MD, \\ Leticia Pereira PhD, Helena Piccinini-Vallis MD PhD, Megha Poddar MD, Paul Poirier MD, Denis Prud'homme MD MSc, \\ Ximena Ramos Salas PhD, Christian Rueda-Clausen MD PhD, Shelly Russell-Mayhew PhD RPsych, Judy Shiau MD, \\ Diana Sherifali RN PhD, John Sievenpiper MD PhD, Sanjeev Sockalingam MD MHPE, Valerie Taylor MD PhD, \\ Ellen Toth MD, Laurie Twells PhD, Richard Tytus MD, Shahebina Walji MD, Leah Walker BA RCT, Sonja Wicklum MD
}

Cite as: CMAJ 2020 August 4;192:E875-91. doi: 10.1503/cmaj.191707

This article is available in French at www.cmaj.ca/lookup/suppl/doi:10.1503/cmaj.191707/-/DC1

CMAJ Podcasts: author interview at https://www.cmaj.ca/lookup/doi/10.1503/cmaj.191707/tab-related-content

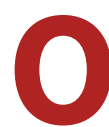

besity is a complex chronic disease in which abnormal or excess body fat (adiposity) impairs health, increases the risk of long-term medical complications and reduces lifespan. ${ }^{1}$ Epidemiologic studies define obesity using the body mass index (BMI; weight/height ${ }^{2}$ ), which can stratify obesity-related health risks at the population level. Obesity is operationally defined as a BMI exceeding $30 \mathrm{~kg} / \mathrm{m}^{2}$ and is subclassified into class 1 (30-34.9), class 2 (35-39.9) and class $3(\geq 40)$. At the population level, health complications from excess body fat increase as BMI increases. ${ }^{2}$ At the individual level, complications occur because of excess adiposity, location and distribution of adiposity and many other factors, including environmental, genetic, biologic and socioeconomic factors (Box 1). ${ }^{11}$

Over the past 3 decades, the prevalence of obesity has steadily increased throughout the world, ${ }^{12}$ and in Canada, it has increased threefold since $1985 .{ }^{13}$ Importantly, severe obesity has increased more than fourfold and, in 2016, affected an estimated 1.9 million Canadian adults. ${ }^{13}$

Obesity has become a major public health issue that increases health care costs ${ }^{14,15}$ and negatively affects physical and psychological health. ${ }^{16}$ People with obesity experience pervasive weight bias and stigma, which contributes (independent of weight or BMI) to increased morbidity and mortality. ${ }^{17}$

\section{KEY POINTS}

- Obesity is a prevalent, complex, progressive and relapsing chronic disease, characterized by abnormal or excessive body fat (adiposity), that impairs health.

- People living with obesity face substantial bias and stigma, which contribute to increased morbidity and mortality independent of weight or body mass index.

- This guideline update reflects substantial advances in the epidemiology, determinants, pathophysiology, assessment, prevention and treatment of obesity, and shifts the focus of obesity management toward improving patient-centred health outcomes, rather than weight loss alone.

- Obesity care should be based on evidence-based principles of chronic disease management, must validate patients' lived experiences, move beyond simplistic approaches of "eat less, move more," and address the root drivers of obesity.

- People living with obesity should have access to evidence-informed interventions, including medical nutrition therapy, physical activity, psychological interventions, pharmacotherapy and surgery.

Obesity is caused by the complex interplay of multiple genetic, metabolic, behavioural and environmental factors, with the latter thought to be the proximate cause of the substantial 


\section{Box 1: Complications of obesity}

Adipose tissue not only influences the central regulation of energy homeostasis, but excessive adiposity can also become dysfunctional and predispose the individual to the development of many medical complications, such as:

- Type 2 diabetes ${ }^{3}$

- Gallbladder disease ${ }^{4}$

- Nonalcoholic fatty liver disease ${ }^{5}$

- Gout $^{6}$

Excess and ectopic body fat are important sources of adipocytokines and inflammatory mediators that can alter glucose and fat metabolism, leading to increased cardiometabolic and cancer risks, and thereby reducing disease-free duration and life expectancy by 6 to 14 years. ${ }^{1,7,8} \mathrm{It}$ is estimated that $20 \%$ of all cancers can be attributed to obesity, independent of diet. ${ }^{9}$ Obesity increases the risk of the following cancers: ${ }^{10}$

- Colon (both sexes)

- Kidney (both sexes)

- Esophagus (both sexes)

- Endometrium (women)

- Postmenopausal breast (women)

rise in the prevalence of obesity. ${ }^{18,19} \mathrm{~A}$ better understanding of the biological underpinnings of this disease has emerged in recent years. ${ }^{19}$ The brain plays a central role in energy homeostasis by regulating food intake and energy expenditure (Box 2). ${ }^{24}$

Decreased food intake and increased physical activity lead to a negative energy balance and trigger a cascade of metabolic and neurohormonal adaptive mechanisms. ${ }^{25,26}$ Therapies that target these alterations in neurohormonal mechanisms can become effective tools in the long-term management of obesity. ${ }^{27}$

Novel approaches to diagnose and assess obesity in clinical practice have been proposed. ${ }^{11,18,19,28}$ Although BMI is widely used to assess and classify obesity (adiposity), it is not an accurate tool for identifying adiposity-related complications. ${ }^{19}$ Waist circumference has been independently associated with an increase in cardiovascular risk, but it is not a good predictor of visceral adipose tissue on an individual basis. ${ }^{29}$ Integration of both BMI and waist circumference in clinical assessment may identify the higher-risk phenotype of obesity better than either BMI or waist circumference alone, particularly in those individuals with lower BMI. ${ }^{30,31}$ In addition to BMI and waist circumference measurements, a comprehensive history to identify the root causes of obesity, appropriate physical examination and relevant laboratory investigations will help to identify those who will benefit from treatment. ${ }^{32}$

The Edmonton obesity staging system has been proposed to guide clinical decisions from the obesity assessment and at each BMI category (Appendix 1, available at www.cmaj.ca/lookup/ suppl/doi:10.1503/cmaj.191707/-/DC2). ${ }^{28}$ This 5-stage system of obesity classification considers metabolic, physical and psychological parameters to determine the optimal obesity treatment. In population studies, it has been shown to be a better predictor of all-cause mortality when compared with BMI or waist circumference measurements alone. ${ }^{33,34}$

\section{Box 2: Appetite regulation ${ }^{20-23}$}

- The control of appetite is complex and involves the integration of the central neural circuits including the hypothalamus (homeostatic control), the mesolimbic system (hedonic control) and the frontal lobe (executive control).

- The crosstalk between homeostatic and hedonic eating is influenced by mediators from adipose tissue, the pancreas, gut and other organs.

- Cognitive functions in the prefrontal cortex exert executive control on food choices and the decision to eat. The interconnectivity of these neural networks drives eating behaviour and has been shown to be altered in obesity.

There is a recognition that obesity management should be about improved health and well-being, and not just weight loss. ${ }^{34-36}$ Because the existing literature is based mainly on weight-loss outcomes, several recommendations in this guideline are weight-loss centred. However, more research is needed to shift the focus of obesity management toward improving patient-centred health outcomes, rather than weight loss alone.

Despite growing evidence that obesity is a serious chronic disease, it is not effectively managed within our current health system. ${ }^{37,38}$ Canadian health professionals feel ill equipped to support people living with obesity. ${ }^{39-41}$ Biased beliefs about obesity also affect the level and quality of health care that patients with obesity receive. ${ }^{42}$ The dominant cultural narrative regarding obesity fuels assumptions about personal irresponsibility and lack of willpower and casts blame and shame upon people living with obesity. ${ }^{41}$ Importantly, obesity stigma negatively influences the level and quality of care for people living with obesity. ${ }^{42}$

With increased knowledge of the disease state and better approaches to assess and manage obesity, it is timely to update the 2006 Canadian clinical practice guideline. ${ }^{43}$ The goal of this update is to disseminate to primary care practitioners evidenceinformed options for assessing and treating people living with obesity. Importantly, this guideline incorporates the perspectives of people with lived experience and of interprofessional primary care providers with those of experts on obesity management, and researchers. This article is a summary of the full guideline, which is available online (http://obesitycanada.ca/guidelines/).

\section{Scope}

The target users for this guideline are primary health care professionals. The guideline may also be used by policy-makers and people affected by obesity and their families. The guideline is focused on obesity in adults. The recommendations are intended to serve as a guide for health care providers; clinical discretion should be used by all who adopt these recommendations. Resource limitations and individual patient preferences may make it difficult to put every recommendation into practice, but the guideline is intended to improve the standard of, and access to, care for individuals with obesity in all regions of Canada. 


\section{OBESI IN ADULTS}

\section{A clinical practice guideline}

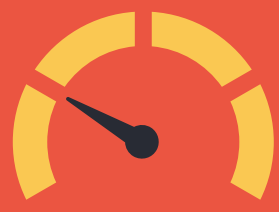

BMI IS NOT AN ACCURATE

TOOL FOR IDENTIFYING

OBESITY-RELATED

COMPLICATIONS

Obesity complex disease in which abnormal or excess body fat impairs health

Effects:

$\nabla$ health $\quad \nabla$ quality of life $\quad \nabla$ lifespan

People with obesity experience weight bias and stigma

Weight bias thinking that people with obesity do not have enough willpower or are not cooperative increased complications and mortality independent of weight or BMI

\section{THE PATIENT JOURNEY IN OBESITY MANAGEMENT}

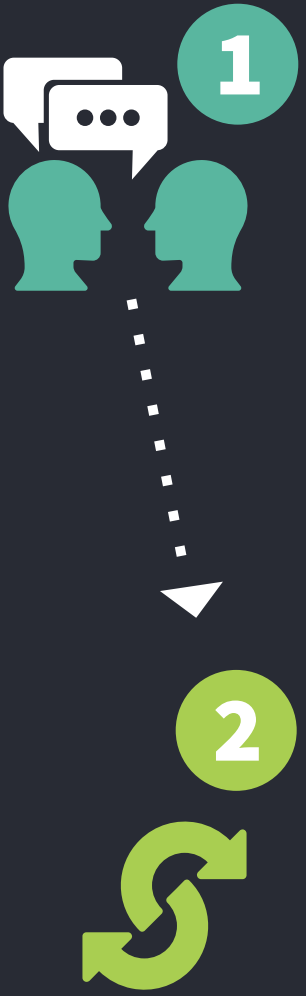

ASK

PERMISSION

"Would it be all right

if we discussed

your weight?"

Asking permission

- Shows compassion and empathy

- Builds patient-provider trust

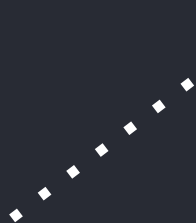

\section{ASSESS THEIR STORY}

- Goals that matter to the patient

- Obesity classification

(BMl and waist circumference)

- Disease severity

(Edmonton Obesity Staging System)
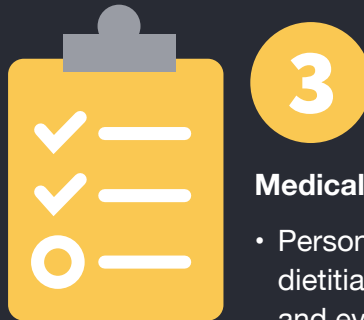

ADVISE ON MANAGEMENT

Medical nutrition therapy

- Personalized counselling by a registered dietitian with a focus on healthy food choices and evidence-based nutrition therapy

Stigma acting on weight-biased beliefs

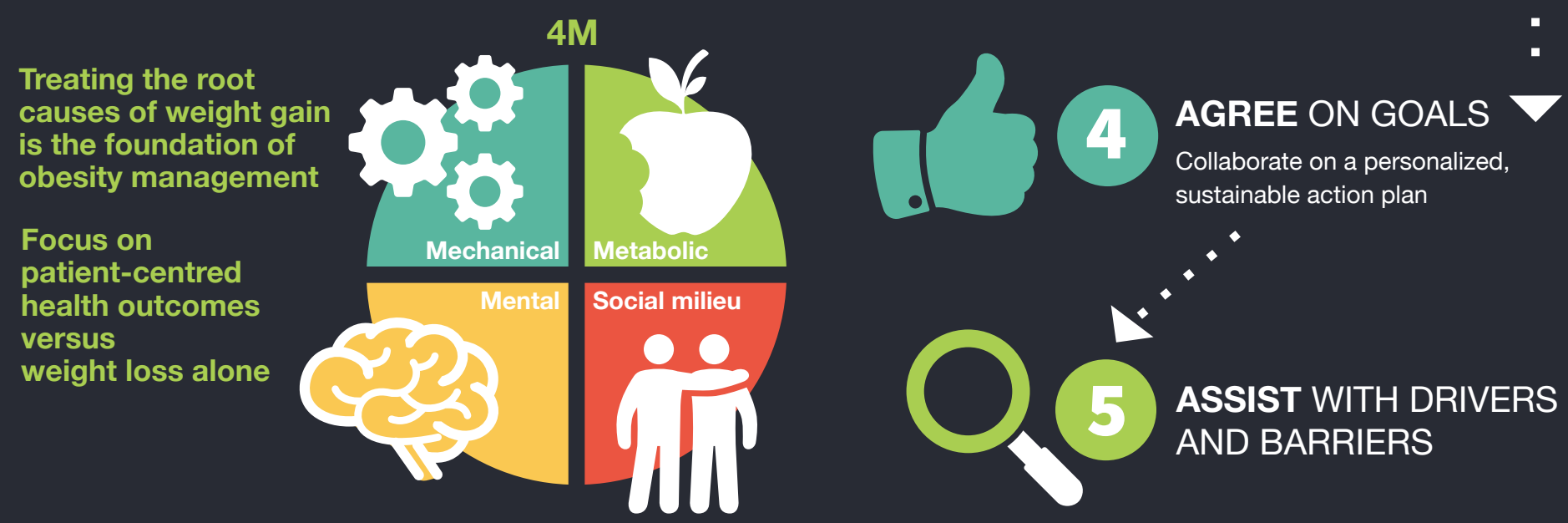

- Cognitive approach to behaviour change

- Manage sleep, time and stress

- Psychotherapy if appropriate

\section{Psychological}

\section{Exercise}

30-60 min of moderate to vigorous activity most days

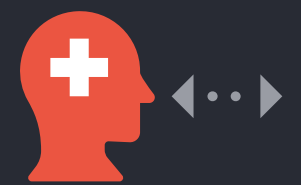




\section{Recommendations}

This clinical practice guideline informs the arc of the patient journey and clinical management approach in the primary care setting. The guideline recommendations are shown in Table 1.

A complete description of the recommendations and supporting evidence are available in the 19 chapters of the full guideline (http://obesitycanada.ca/guidelines/). This synopsis outlines a discussion of the guiding principles that the executive committee determined as important for advancing clinical practice in Canada.

There are 5 steps in the patient arc to guide a health care provider in the care of people living with obesity. Each step is outlined below with highlights of the relevant recommendations and a discussion of supporting evidence.

1. Recognition of obesity as a chronic disease by health care providers, who should ask the patient permission to offer advice and help treat this disease in an unbiased manner.

2. Assessment of an individual living with obesity, using appropriate measurements, and identifying the root causes, complications and barriers to obesity treatment.

3. Discussion of the core treatment options (medical nutrition therapy and physical activity) and adjunctive therapies that may be required, including psychological, pharmacologic and surgical interventions.

4. Agreement with the person living with obesity regarding goals of therapy, focusing mainly on the value that the person derives from health-based interventions.

5. Engagement by health care providers with the person with obesity in continued follow-up and reassessments, and encouragement of advocacy to improve care for this chronic disease.

\section{Step 1: Recognition of obesity as a chronic disease and obtaining patient permission}

Primary care providers should recognize and treat obesity as a chronic disease, caused by abnormal or excess body fat accumulation (adiposity), which impairs health, with increased risk of premature morbidity and mortality. ${ }^{1,2,18,44-47}$

Obesity is a complex and heterogeneous chronic disease that does not present in the same way in all patients and that requires individualized treatment and long-term support like any other complex chronic disease.

Weight bias in health care settings can reduce the quality of care for patients living with obesity. ${ }^{42} \mathrm{~A}$ key to reducing weight bias, stigma and discrimination in health care settings is for health care providers to be aware of their own attitudes and behaviours toward individuals living with obesity. ${ }^{48}$ This can be achieved by completing a self-assessment tool, like the Implicit Association Test, for weight bias. ${ }^{49} \mathrm{~A}$ full description and supporting evidence for weight bias recommendations are available online (http://obesitycanada. ca/guidelines/) in the chapter titled "Reducing weight bias in obesity management, practice and policy."

Health care providers should not assume that all patients living with obesity are prepared to initiate obesity management. Health care providers should ask the patient permission to discuss obesity, and if the patient permits, then a discussion on treatment can begin. ${ }^{50,51}$

\section{Step 2: Assessment}

Primary care clinicians should promote a holistic approach to health with a focus on health behaviours in all patients and address the root causes of weight gain with care to avoid stigmatizing and overly simplistic narratives.

Direct measurement of height, weight and waist circumference and calculation of BMI should be included in routine physical examination for all adults. Although BMI has its limitations, it remains a valuable tool for screening purposes and for population health indices. ${ }^{52}$ For persons with increased BMI (between $25 \mathrm{mg} / \mathrm{m}^{2}$ and $34.9 \mathrm{mg} / \mathrm{m}^{2}$ ), waist circumference should be regularly measured to identify individuals with increased visceral adiposity and adiposity-related health risks. ${ }^{53}$

Root causes of obesity include biological factors such as genetics, epigenetics, neurohormonal mechanisms, associated chronic diseases and obesogenic medications, sociocultural practices and beliefs, social determinants of health, built environment, individual life experiences like adverse childhood experiences, and psychological factors such as mood, anxiety, binge-eating disorder, attention-deficit/hyperactivity disorder, self-worth and identity. ${ }^{50}$ Working with people to understand their context and culture, and integrate their root causes, allows for the development of personalized plans. These plans can be integrated into long-term therapeutic relationships with chronic disease follow-up of obesity and related comorbidities, including addressing the root causes of obesity such as existing conditions and obesogenic medications.

We recommend obtaining a comprehensive history to identify these root causes of weight gain, as well as physical, mental and psychosocial barriers. Physical examination, laboratory, diagnostic imaging and other investigations should be carried out based on clinical judgment. We also recommend measuring blood pressure in both arms and obtaining fasting glucose or glycated hemoglobin values and a lipid panel to determine cardiometabolic risk, and when indicated, alanine aminotransferase to screen for nonalcoholic fatty liver disease.

\section{Step 3: Discussion of treatment options}

Adults living with obesity should receive individualized care plans that address their root causes of obesity and that provide support for behavioural change (e.g., nutrition, physical activity) and adjunctive therapies, which may include psychological, pharmacologic and surgical interventions.

\section{Nutrition and exercise}

All individuals, regardless of body size or composition, would benefit from adopting a healthy, well-balanced eating pattern and engaging in regular physical activity. Aerobic activity (30$60 \mathrm{~min}$ ) on most days of the week can lead to a small amount of weight and fat loss, improvement in cardiometabolic parameters, and weight maintenance after weight loss. ${ }^{54}$

Weight loss and weight-loss maintenance require a long-term reduction in caloric intake. Long-term adherence to a healthy eating pattern that is personalized to meet individual values and preferences, while fulfilling nutritional needs and treatment goals, is an important element of managing health and weight. 
Medical nutrition therapy is a foundation for chronic disease management, including obesity management. ${ }^{55,56}$ However, medical nutrition therapy should not be used in isolation in obesity management, as sustaining weight loss may be difficult long term because of compensatory mechanisms in the brain that promote positive caloric intake by increasing hunger and ultimately causing weight gain. ${ }^{57,58}$ Instead, medical nutrition therapy, in combination with other interventions (psychological, pharmacologic, surgical), should be tailored to meet an individual's health-related or weight-related outcomes. .6,59 $^{5}$

The weight loss achieved with health behavioural changes is usually $3 \%-5 \%$ of body weight, which can result in meaningful improvement in obesity-related comorbidities. ${ }^{60}$ The amount of weight loss varies substantially among individuals, depending on biological and psychosocial factors and not simply on individual effort.

Table 1 (part 1 of 5): Recommendations on management of obesity in adults*

Recommendations

\section{Reducing weight bias in obesity management, practice and policy} Health care providers should assess their own attitudes and beliefs regarding obesity and consider how their attitudes and beliefs may influence care delivery.

$2 \quad$ Health care providers may recognize that internalized weight bias (bias toward oneself) in people living with obesity can affect behavioural and health outcomes.

3 Health care providers should avoid using judgmental words (level $1 \mathrm{a}$, grade A), images (level 2b, grade B) and practices (level 2a, grade B) when working with patients living with obesity.

4 We recommend that health care providers avoid making assumptions that an ailment or complaint a patient presents with is related to their body weight.

\section{Epidemiology of adult obesity}

$5 \quad$ Health care providers can recognize and treat obesity as a chronic disease, caused by abnormal or excess body fat accumulation (adiposity), which impairs health, with increased risk of premature morbidity and mortality.

6 The development of evidence-informed strategies at the health system and policy levels can be directed at managing obesity in adults.

7 Continued longitudinal national and regional surveillance of obesity that includes self-reported and measured data (i.e., height, weight, waist circumference) may be collected on a regular basis.

\section{Enabling participation in activities of daily living for people living with obesity}

8 We recommend that health care providers ask people living with obesity if they have concerns about managing self-care activities, such as bathing, getting dressed, bowel and bladder management, skin and wound care, and foot care.

9 We recommend that health care providers assess fall risk in people living with obesity, as this could interfere with their ability and interest in participating in physical activity.

\section{Assessment of people living with obesity}

10 We suggest that health care providers involved in screening, assessing and managing people living with obesity use the 5 As framework (see Appendix $2 \ddagger$ ) to initiate the discussion by asking for their permission and assessing their readiness to begin treatment.

11 Health care providers can measure height, weight and calculate the BMI in all adults (level 2a, grade B), and measure waist circumference in individuals with a BMI $25-35 \mathrm{~kg} / \mathrm{m}^{2}$ (level $2 \mathrm{~b}$, grade B).

12 We suggest that a comprehensive history to identify root causes of weight gain as well as complications of obesity and potential barriers to treatment be included in the assessment.

13 We recommend measuring blood pressure in both arms, fasting glucose or glycated hemoglobin and lipid profile to determine cardiometabolic risk and, where appropriate, ALT to screen for nonalcoholic fatty liver disease in people living with obesity.

14 We suggest that health care providers consider using the Edmonton Obesity Staging System (see Appendix 1)§ to determine the severity of obesity and guide clinical decision-making.

\section{The role of mental health in obesity management}

15 We recommend regular monitoring of weight, glucose and lipid profile in people with a mental health diagnosis and who are taking medications associated with weight gain.

16 Health care providers may consider both efficacy and effects on body weight when choosing psychiatric medications.

17 Metformin and psychological treatment such as cognitive behavioural therapy should be considered for prevention of weight gain in people with severe mental illness who are treated with antipsychotic medications associated with weight gain.

18 Health care providers should consider lisdexamfetamine and topiramate as an adjunct to psychological treatment to reduce eating pathology and weight in people with overweight or obesity and binge-eating disorder.
Category of evidence and strength of recommendationt

Level 1a, grade $\mathrm{A}$

Level 2a, grade B

See recommendation

Level 3, grade C

Level $2 b$, grade $B$

Level $2 b$, grade B

Level $2 b$, grade $B$

Level 3, grade C

Level 3, grade C

Level 4, grade D

(consensus)

See recommendation

Level 4, grade D

Level 3, grade D

Level 4, grade D

Level 3, grade C

Level 2a, grade B

Level 1a, grade A

Level $1 \mathrm{a}$, grade $\mathrm{A}$ 


\section{Table 1 (part 2 of 5 ): Recommendations on management of obesity in adults}

Recommendations

\section{Medical nutrition therapy in obesity management}

19 We suggest that nutrition recommendations for adults of all body sizes be personalized to meet individual values, preferences and treatment goals to support a dietary approach that is safe, effective, nutritionally adequate, culturally acceptable and affordable for long-term adherence.

20 Adults living with obesity should receive individualized medical nutrition therapy provided by a registered dietitian (when available) to improve weight outcomes (body weight, BMI), waist circumference, glycemic control, established lipid, and blood pressure targets.

21 Adults living with obesity and impaired glucose tolerance (prediabetes) or type 2 diabetes may receive medical nutrition therapy provided by a registered dietitian (when available) to reduce body weight and waist circumference and improve glycemic control and blood pressure.

22 Adults living with obesity can consider any of multiple medical nutrition therapies to improve health-related outcomes, choosing the dietary patterns and food-based approaches that support their best long-term adherence. (Full recommendation and category and level of evidence available in the chapter titled "Medical nutrition therapy in obesity management.")

23 Adults living with obesity and impaired glucose tolerance (prediabetes) should consider intensive behavioural interventions that target a 5\%-7\% weight loss, to improve glycemic control, blood pressure and blood lipid targets (level 1a, grade A) and reduce the incidence of type 2 diabetes (level 1a, grade A), microvascular complications (retinopathy, nephropathy and neuropathy) (level 1a, grade B), and cardiovascular and all-cause mortality (level 1a, grade B).

24 Adults living with obesity and type 2 diabetes should consider intensive lifestyle interventions that target a $7 \%-15 \%$ weight loss, to increase the remission of type 2 diabetes and reduce the incidence of nephropathy, obstructive sleep apnea and depression.

25 We recommend a nondieting approach to improve quality of life, psychological outcomes (general well-being, body image perceptions), cardiovascular outcomes, body weight, physical activity, cognitive restraint and eating behaviours.

\section{Physical activity in obesity management}

26 Aerobic physical activity (30-60 minutes of moderate to vigorous intensity most days of the week) can be considered for adults who want to:

- Achieve small amounts of body weight and fat loss (level 2a, grade B)

- Achieve reduction in abdominal visceral fat (level 1a, grade A) and ectopic fat, such as liver and heart fat (level 1a, grade A), even in the absence of weight loss

- Favour weight maintenance after weight loss (level 2a, grade B)

- Favour the maintenance of fat-free mass during weight loss (level 2a, grade B)

- Increase cardiorespiratory fitness (level 2a, grade B) and mobility (level 2a, grade B).

27 For adults living with overweight or obesity, resistance training may promote weight maintenance or modest increases in muscle mass or fat-free mass and mobility.

28 Increasing exercise intensity, including high-intensity interval training, can achieve greater increases in cardiorespiratory fitness and reduce the amount of time required to achieve benefits similar to those from moderate-intensity aerobic activity.

29 Regular physical activity, with and without weight loss, can improve many cardiometabolic risk factors in adults who have overweight or obesity, including hyperglycemia and insulin sensitivity (level $2 b$, grade B), high blood pressure (level 1a, grade B) and dyslipidemia (level 2a, grade B).

30 Regular physical activity can improve health-related quality of life, mood disorders (i.e., depression, anxiety) and body image in adults living with overweight or obesity.

\section{Effective psychological and behavioural interventions in obesity management}

31 Multicomponent psychological interventions (combining behaviour modification [goal-setting, self-monitoring, problem-solving], cognitive therapy [reframing] and values-based strategies to alter diet and activity) should be incorporated into care plans for weight loss, and improved health status and quality of life (level 1a, grade A) in a manner that promotes adherence, confidence and intrinsic motivation (level $1 \mathrm{~b}$, grade $\mathrm{A}$ ).

32 Health care providers should provide longitudinal care with consistent messaging to people living with obesity in order to support the development of confidence in overcoming barriers (self-efficacy) and intrinsic motivation (personal, meaningful reasons to change), to encourage the patient to set and sequence health goals that are realistic and achievable, to self-monitor behaviour and to analyze setbacks using problem-solving and adaptive thinking (cognitive reframing), including clarifying and reflecting on values-based behaviours.

33 Health care providers should ask people living with obesity for permission to educate them that success in obesity management is related to improved health, function and quality of life resulting from achievable behavioural goals and not on the amount of weight loss.

34 Health care providers should provide follow-up sessions consistent with repetition and relevance to support the development of self-efficacy and intrinsic motivation. (Full recommendation is available in the chapter titled "Effective psychological and behavioural interventions in obesity management.")

Level 2a, grade B

Level 2a, grade B

See recommendation

Level $2 \mathrm{~b}$, grade $\mathrm{B}$

See recommendation

Level 1a, grade A

Level 1a, grade A

Level 1a, grade A 


\section{Pharmacotherapy in obesity management}

35 Pharmacotherapy for weight loss can be used for persons with $\mathrm{BMI} \geq 30 \mathrm{~kg} / \mathrm{m}^{2}$ or $\mathrm{BMI} \geq 27 \mathrm{~kg} / \mathrm{m}^{2}$ with adiposity-related complications, in conjunction with medical nutrition therapy, physical activity and psychological interventions (liraglutide $3.0 \mathrm{mg}$, naltrexone-bupropion combination, orlistat).

36 Pharmacotherapy may be used to maintain weight loss that has been achieved by health behaviour changes, and to prevent weight regain (liraglutide $3.0 \mathrm{mg}$ or orlistat).

37 For people living with type 2 diabetes and a BMI $\geq 27 \mathrm{~kg} / \mathrm{m}^{2}$, pharmacotherapy can be used in conjunction with health behaviour changes for weight loss and improvement in glycemic control: liraglutide $3.0 \mathrm{mg}$ (level 1a, grade A), naltrexone-bupropion combination (level 2a, grade B), orlistat (level 2a, grade B).

38 We recommend pharmacotherapy in conjunction with health behaviour changes for people living with prediabetes and overweight or obesity $\left(\mathrm{BMI} \geq 27 \mathrm{~kg} / \mathrm{m}^{2}\right.$ ) to delay or prevent type 2 diabetes (liraglutide $3.0 \mathrm{mg}$; orlistat).

39 We do not suggest the use of prescription or over-the-counter medications other than those approved for weight management.

40 For people living with overweight or obesity who require pharmacotherapy for other health conditions, we suggest choosing drugs that are not associated with weight gain.

Level 2a, grade B

Level 2a, grade B

See recommendation

Level 2a, grade B

Level 4, grade D

(consensus)

Level 4 , grade D

(consensus)

\section{Bariatric surgery: selection and preoperative workup}

41 We suggest that a comprehensive medical and nutritional evaluation be completed and nutrient deficiencies corrected in candidates for bariatric surgery.

42 Preoperative smoking cessation can minimize perioperative and postoperative complications.

43 We suggest screening for and treatment of obstructive sleep apnea in people seeking bariatric surgery.

\section{Bariatric surgery: surgical options and outcomes}

44 Bariatric surgery can be considered for people with $\mathrm{BMI} \geq 40 \mathrm{~kg} / \mathrm{m}^{2}$ or $\mathrm{BMI} \geq 35 \mathrm{~kg} / \mathrm{m}^{2}$ with at least 1 adiposity-related disease (level 4, grade $\mathrm{D}$, consensus) to:

- Reduce long-term overall mortality (level 2b, grade B)

- Induce significantly better long-term weight loss compared with medical management alone (level 1a, grade A)

- Induce control and remission of type 2 diabetes, in combination with best medical management, over best medical management alone (level 2a, grade B)

- Significantly improve quality of life (level 3 , grade C)

- Induce long-term remission of most adiposity-related diseases, including dyslipidemia (level 3, grade C), hypertension (level 3, grade C), liver steatosis and nonalcoholic steatohepatitis (level 3, grade C).

45 Bariatric surgery should be considered in patients with poorly controlled type 2 diabetes and class I obesity (BMI between 30 and $35 \mathrm{~kg} / \mathrm{m}^{2}$ ) despite optimal medical management.

46 Bariatric surgery may be considered for weight loss and/or to control adiposity-related diseases in persons with class 1 obesity, in whom optimal medical and behavioural management has been insufficient to produce significant weight loss.

47 We suggest that the choice of bariatric procedure (sleeve gastrectomy, gastric bypass or duodenal switch) be decided according to the patient's need, in collaboration with an experienced interprofessional team.

48 We suggest that adjustable gastric banding not be offered owing to unacceptable complications and long-term failure.

49 We suggest that single anastomosis gastric bypass not be routinely offered, owing to long-term complications in comparison with Roux-en-Y gastric bypass.

\section{Bariatric surgery: postoperative management}

50 Health care providers can encourage persons who have undergone bariatric surgery to participate in and maximize their access to behavioural interventions and allied health services at a bariatric surgical centre.

51 We suggest that bariatric surgical centres communicate a comprehensive care plan to primary care providers for patients who are discharged, including bariatric procedure, emergency contact numbers, annual blood tests required, long-term vitamin and minerals supplements, medications and behavioural interventions, as well as when to refer back.

52 We suggest that after a patient has been discharged from the bariatric surgical centre, primary care providers conduct annual review of the following: weight, nutritional intake, activity, adherence to multivitamin and mineral supplements, assessment of comorbidities and laboratory tests to assess and treat for nutritional deficiencies as required.

53 We suggest that primary care providers consider referral back to the bariatric surgical centre or to a local specialist for technical or gastrointestinal symptoms, nutritional issues, pregnancy, psychological support, weight regain or other medical issues related to bariatric surgery, as described in the chapter titled "Bariatric surgery: postoperative management.

54 We suggest that bariatric surgical centres provide follow-up and appropriate laboratory tests at regular intervals postsurgery with access to appropriate health care professionals (dietitian, nurse, social worker, bariatric physician, surgeon, psychologist or psychiatrist) until discharge is deemed appropriate for the patient.

Level 4 , grade D

Level 2a, grade B

Level 4 , grade $D$

See recommendation

Level 1a, grade $\mathrm{A}$

Level 2a, grade B

Level 4 , grade $D$

(consensus)

Level 4 , grade D

Level 4 , grade $D$

Level $2 a$, grade $B$

Level 4 , grade D

(consensus)

Level 4, grade D

(consensus)

Level 4, grade D (consensus)

Level 4, grade D (consensus) 


\section{Primary care and primary health care in obesity management}

55 We recommend that primary care clinicians identify people with overweight and obesity, and initiate patient-centred, health-focused conversations with them.

56 We recommend that health care providers ensure they ask people for their permission before discussing weight or taking anthropometric measurements.

57 Primary care interventions should be used to increase health literacy in individuals' knowledge and skill about weight management as an effective intervention to manage weight.

58 Primary care clinicians should refer persons with overweight or obesity to primary care multicomponent programs with personalized obesity management strategies as an effective way to support obesity management.

59 Primary care clinicians can use collaborative deliberation with motivational interviewing to tailor action plans to individuals' life context in a way that is manageable and sustainable to support improved physical and emotional health, and weight management.

60 Interventions that target a specific ethnic group should consider the diversity of psychological and social practices with regard to excess weight, food and physical activity, as well as socioeconomic circumstances, as they may differ across and within different ethnic groups.

61 Longitudinal primary care interventions should focus on incremental, personalized, small behaviour changes (the "small change approach") to be effective in supporting people to manage their weight.

62 Primary care multicomponent programs should consider personalized obesity management strategies as an effective way to support people living with obesity.

63 Primary care interventions that are behaviour based (nutrition, exercise, lifestyle), alone or in combination with pharmacotherapy, should be used to manage overweight and obesity.

64 Group-based diet and physical activity sessions informed by the Diabetes Prevention Program and the Look AHEAD (Action for Health in Diabetes) programs should be used as an effective management option for adults with overweight and obesity.

65 Interventions that use technology to increase reach to larger numbers of people asynchronously should be a potentially viable lower cost intervention in a community-based setting.

66 Educators of undergraduate, graduate and continuing education programs for primary health care professionals should provide courses and clinical experiences to address the gaps in skills, knowledge of the evidence, and attitudes necessary to confidently and effectively support people living with obesity.

\section{Commercial products and programs in obesity management}

67 For adults living with overweight or obesity, the following commercial programs should achieve mild to moderate weight loss in the short or medium term, compared with usual care or education:

- WW (formerly Weight Watchers) (level 1a, grade A)

- Optifast (level 1b, grade B)

- Jenny Craig (level $1 \mathrm{~b}$, grade B)

- Nutrisystem (level $1 b$, grade B)

68 Optifast, Jenny Craig, WW (formerly Weight Watchers) and Nutrisystem should achieve a mild reduction of glycated hemoglobin values over a short-term period compared with usual counselling in adults with obesity and type 2 diabetes.

69 We do not recommend the use of over-the-counter commercial weight-loss products for obesity management, owing to lack of evidence.

70 We do not suggest that commercial weight-loss programs be used for improvement in blood pressure and lipid control in adults living with obesity.

\section{Emerging technologies and virtual medicine in obesity management}

71 Implementation of management strategies can be delivered through Web-based platforms (e.g., online education on medical nutrition therapy and physical activity) or mobile devices (e.g., daily weight reporting through a smartphone application) in the management of obesity.

72 We suggest that health care providers incorporate individualized feedback and follow-up (e.g., personalized coaching or feedback via phone or email) into technology-based management strategies to improve weight-loss outcomes.

73 The use of wearable activity tracking technology should be part of a comprehensive strategy for weight management.

Level 3, grade C

Level 3, grade C

Level 1a, grade $\mathrm{A}$

Level $1 \mathrm{~b}$, grade $\mathrm{B}$

Level $2 b$, grade $C$

Level $1 b$, grade $B$

Level $1 b$, grade B

Level $1 \mathrm{~b}$, grade $B$

Level 1a, grade A

Level $1 \mathrm{~b}$, grade $\mathrm{A}$

Level $1 b$, grade $B$

Level 1a, grade A

See recommendation

Level $1 b$, grade $B$

Level 4, grade D

Level 4, grade D

Level 2a, grade $B$

Level 4, grade D

Level 1a, grade A 


\section{Weight management over the reproductive years for adult women living with obesity}

74 We recommend that primary care providers discuss weight-management targets specific to the reproductive years with adult women with obesity: preconception weight loss (level 3, grade C); gestational weight gain of $5 \mathrm{~kg}$ to $9 \mathrm{~kg}$ over the entire pregnancy (level 4, grade D); postpartum weight loss of - at minimum - gestational weight gain (level 3 , grade $\mathrm{C}$ ) to reduce the risk of adverse outcomes in the current or in a future pregnancy.

75 Primary care providers should offer behaviour change interventions including both nutrition and physical activity to adult women with obesity who are considering a pregnancy (level 3 , grade C), who are pregnant (level 2a, grade B) and who are postpartum (level 1a, grade A) in order to achieve weight targets.

76 We recommend that primary care providers encourage and support pregnant women with obesity to consume foods consistent with a healthy dietary pattern in order to meet their target gestational weight gain.

77 We recommend that primary care providers encourage and support pregnant women with obesity who do not have contraindications to exercise during pregnancy to engage in at least 150 minutes per week of moderate intensity physical activity, to assist in the management of gestational weight gain.

78 Health care providers should not prescribe metformin for gestational weight gain in pregnant women with obesity (level $1 \mathrm{~b}$, grade A). We suggest that weight-management medications not be used during pregnancy or breastfeeding (level 4, grade D).

79 We recommend that women with obesity be offered additional breastfeeding support because of decreased rates of initiation and continuation.

\section{Obesity management and Indigenous Peoples}

80 We suggest that health care providers for Indigenous people living with obesity:

- Engage with the patient's social realities.

- Validate the patient's experiences of stress and systemic disadvantage influencing poor health and obesity, exploring elements of their environment where reduced stress could shift behaviours.

- Advocate for access to obesity-management resources within publicly funded health care systems, recognizing that resources beyond may be unaffordable and unattainable for many.

- Help patients recognize that good health is attainable, and they are entitled to it.

- Negotiate small, attainable steps relevant to the patient's context.

- Address resistance, seeming apathy and paralysis in patients and providers.

- Self-reflect on anti-Indigenous sentiment common within health care systems, exploring patient motivations and mental health (e.g., trauma, grief) as alternative understandings of causes and solutions to their health problems. Explore one's own potential for bias influenced by systemic racism.

- Expect patient mistrust in health systems; reposition themselves as a helper to the patient instead of as an expert, which may stir resistance and be a barrier to patients' wellness.

- When resistance, seeming apathy and paralysis are encountered, explore patient mental and emotional health needs, which have unique drivers and presentations in many Indigenous contexts.

- Build complex knowledge by healing relationships.

- Build patient knowledge and capacity for obesity self-management through longitudinal explorations of cooccurring health, social, environmental and cultural factors. Strive to build relationships that incorporate healing from multigenerational trauma that, owing to residential schools and child welfare system involvement, may more frequently include sexual abuse.

- Build their own knowledge regarding the health legacy of colonization - including ongoing experiences of anti-Indigenous discrimination within systems and wider society - to facilitate relationships built on mutual understanding.

- Ensure knowledge provided is congruent with the patient's perspectives and educational level, and is learner centred, including potential for patient anticipation of racism or unequal treatment.

- Connect to behaviour, the body and Indigenous ways of knowing, doing and being.

- Elicit and incorporate the patient's individual and community-based concepts of health and healthy behaviours in relation to body size, activity and food preferences (e.g., preference for or scarce access to land-based foods and activities).

- Deeply engage in learning of common values and principles regarding communication and knowledge-sharing in Indigenous contexts (e.g., relationalism, noninterference).

Note: $\mathrm{ALT}=$ alanine aminotransferase, $\mathrm{BMI}=$ body mass index.

*A complete description of the recommendations and supporting evidence is available at http://obesitycanada.ca/guidelines/. Table 3 provides definitions for the actionable verbs used in these recommendations.

†For the classification scheme for category of evidence and strength of evidence, see Box 3.

łAppendix 2 is available at www.cmaj.ca/lookup/suppl/doi:10.1503/cmaj.191707/-/DC2

$\S$ See Appendix 1. 
The weight at which the body stabilizes when engaging in healthy behaviours can be referred to as the "best weight"; this may not be an "ideal" weight on the BMI scale. Achieving an "ideal" BMI may be very difficult. If further weight loss is needed to improve health and well-being beyond what can be achieved with behavioural modification, then more intensive pharmacologic and surgical therapeutic options can be considered.

\section{Psychological and behavioural interventions}

All health interventions such as healthy eating and physical activity strategies, medication adherence or surgery preparation and adjustment approaches rest on behaviour change. ${ }^{61}$ Psychological and behavioural interventions are the "how to" of change. They empower the clinician to guide the patient toward recommended behaviours that can be sustained over time. ${ }^{60} \mathrm{~A}$ full description of psychological and behavioural interventions and supporting evidence are available online (http://obesitycanada. ca/guidelines/) in the chapter titled "Effective psychological and behavioural interventions in obesity management."

\section{Pharmacotherapy}

We recommend adjunctive pharmacotherapy for weight loss and weight-loss maintenance for individuals with $\mathrm{BMI} \geq 30 \mathrm{~kg} / \mathrm{m}^{2}$ or BMI $\geq 27 \mathrm{~kg} / \mathrm{m}^{2}$ with adiposity-related complications, to support medical nutrition therapy, physical activity and psychological interventions. Options include liraglutide $3.0 \mathrm{mg}$, naltrexone-bupropion combination and orlistat. Pharmacotherapy augments the magnitude of weight loss beyond that which health behaviour changes can achieve alone and is important in the prevention of weight regain. ${ }^{62-66} \mathrm{~A}$ full description and supporting evidence are available online (http://obesitycanada.ca/ guidelines/) in the chapter titled "Pharmacotherapy in obesity management."

\section{Bariatric surgery}

Bariatric surgery may be considered for people with $\mathrm{BMI} \geq 40 \mathrm{~kg} / \mathrm{m}^{2}$ or $\mathrm{BMI} \geq 35 \mathrm{~kg} / \mathrm{m}^{2}$ with at least 1 obesity-related disease. The decision regarding the type of surgery should be made in collaboration with a multidisciplinary team, balancing the patient's expectations, medical condition, and expected benefits and risks of the surgery. A full description and supporting evidence are available online (http://obesitycanada.ca/guidelines/) in the chapters titled "Bariatric surgery: selection and preoperative workup," "Bariatric surgery: options and outcomes" and "Bariatric surgery: postoperative management."

\section{Step 4: Agreement regarding goals of therapy}

Because obesity is a chronic disease, managing it in the long term involves patient-provider collaboration. ${ }^{67}$ Health care providers should talk with their patients and agree on realistic expectations, person-centred treatments and sustainable goals for behaviour change and health outcomes. ${ }^{68}$

Helpful actions in primary care consultations to mitigate antifat stigma include explicitly acknowledging the multiple determinants of weight-disrupting stereotypes of personal failure or success attached to body composition; focusing on behavioural interventions to improve overall health; and redefining success as healthy behaviour change regardless of body size or weight. ${ }^{69}$

As this disease is chronic in nature, the treatment plan must be long term. Health care providers and patients should design and agree on a personalized action plan that is practical and sustainable and addresses the drivers of weight gain. ${ }^{70}$

\section{Step 5: Follow-up and advocacy}

There is a need to advocate for more effective care for people living with obesity. This includes improving the education and lifelong learning of health care providers to be able to deliver effective, evidence-based obesity care. We also need to support allocation of health care resources to improve access to effective behavioural, pharmacologic and surgical therapeutic options.

There are substantial barriers affecting access to obesity care in Canada, including a profound lack of interdisciplinary obesity management programs, a lack of adequate access to health care providers with expertise in obesity, long wait times for referrals and surgery, and the high costs of some treatments. ${ }^{37,71-73}$ In general, health care professionals are poorly prepared to treat obesity. ${ }^{74}$ None of the anti-obesity medications available in Canada is listed as a benefit on any provincial or territorial formulary and none is covered under any provincial public drug benefit or pharmacare program. ${ }^{71}$ Wait times for bariatric surgery in Canada are the longest of any surgically treatable condition. ${ }^{37,71}$ Although access to bariatric surgery has increased in some parts of Canada, it is still limited in most provinces and nonexistent in the 3 territories. ${ }^{37,71,75}$ Patients referred to bariatric surgery can wait as long as 8 years before meeting a specialist or receiving the surgery.

The lack of access to obesity treatments is contributing to rising levels of severe obesity in Canada. ${ }^{46}$ Canadians affected by obesity are left to navigate a complex landscape of weight-loss products and services, many of which lack a scientific rationale and openly promote unrealistic and unsustainable weight-loss goals. ${ }^{76}$

\section{Methods}

\section{Composition of participating groups}

Obesity Canada and the Canadian Association of Bariatric Physicians and Surgeons assembled an executive committee and steering committee with broad expertise and geographic representation. The executive committee (comprising 2 co-chairs [S.W., D.C.W.L.], a primary care physician [D.C.-S.], a psychologist [M.V.], a bariatric surgeon [L.B.] and a nephrologist [A.M.S.]) provided overall vision and oversight for the guideline process.

The steering committee $(n=16)$ consisted of some lead authors of each chapter and a person living with obesity; this committee identified additional researchers (chapter leads and authors) to write each chapter. The executive committee and steering committee met in person in April 2017 and December 2017 and at least monthly by phone.

Chapter leads and chapter authors $(n=60)$ were selected based on their expertise in clinical practice and research in the field of obesity medicine. The number of chapter authors per chapter ranged from 2 to 4 . Some chapter leads identified additional authors to participate in writing each chapter. 
Table 2: Summary of guideline development process

Activity

Responsible group

- Mind-mapping exercise to identify the scope of the guideline and the broad sections and chapters (19 chapters)

- Develop research questions (PICO[T]) for each chapter

- Conduct literature search ${ }^{77}$

- Load results of the literature search into the Distiller Systematic Review software program

- Conduct critical appraisal of all papers ${ }^{77}$

- Review results of critical appraisal and assign evidence grades to each paper using AGREE II tool ${ }^{78}$

- Develop reports with graded evidence

- Develop recommendations based on the highest level of evidence and expert consensus

- Review recommendations to ensure fidelity with the evidence (only for recommendations using grade $\mathrm{A}-\mathrm{C}$ level evidence)

- Review recommendations to ensure fidelity with the evidence and relevance to primary care health care professionals

- Revise recommendations based on feedback from the executive committee and MERST

- Review and approve final recommendations

- External review of recommendations to assess relevance and feasibility

- External peer review of chapters

Executive committee

Steering committee

MERST

MERST

Chapter leads

MERST

MERST

Steering Committee with chapter leads and authors MERST

Executive committee

Steering committee with chapter leads

Executive committee

Family physicians and people living with obesity

Experts in each area

Note: AGREE = Appraisal of Guidelines for Research and Evaluation, MERST = McMaster Evidence Review and Synthesis Team; PICO(T) = Population, Intervention, Comparison, Outcome, Time.

We engaged people living with obesity $(n=7)$ through participation of the Public Engagement Committee of Obesity Canada. One member of the Public Engagement Committee (I.P.) was assigned to the steering committee for this guideline. The Public Engagement Committee met by phone once per month. We obtained contributions from committee members through online surveys, focus groups and individual conversations.

We engaged Indigenous community members through a focus group ( $n=14$ ). Additionally, we obtained the insights of health care providers working with Indigenous communities via a consensus-building process between these clinicians and chapter authors, carried out over the spring of 2019, which further grounded evidence in clinical practice. Details are available online (http://obesitycanada.ca/guidelines/) in the chapter titled "Obesity management with Indigenous Peoples."

Obesity Canada staff, consultants and volunteers $(n=15)$ provided administrative support and project coordination for the guideline development process. Table 2 outlines the guideline development process and the responsibilities of each group of participants.

\section{Selection of priority topics}

The executive committee conducted a mind-mapping exercise to identify the scope of the guideline and the broad sections and chapters (April-June 2017). ${ }^{79} \mathrm{~A}$ total of 19 different sections and chapters were prioritized. The steering committee developed $\mathrm{PI} /$ PECOT (Population, Intervention or Exposure, Comparison, Outcome, Time) questions for each chapter at an in-person meeting on Dec. 15-16, 2017, resulting in 179 questions to guide the literature search. All clinical questions were developed with the assistance of the McMaster Evidence Review and Synthesis Team (MERST; previously the McMaster Evidence-Based Practice Centre) in the appropriate format (e.g., PICO [T] for therapeutics and treatments, PEO for qualitative questions).

\section{Literature review and quality assessment}

The McMaster Evidence Review and Synthesis Team supported the guideline development through literature searches based on the PI/PECOT questions for each chapter. A health sciences librarian, based at McMaster Health Sciences Library (Hamilton, Ont.), used this information to create search strategies for the MEDLINE and Embase databases. The searches were for peer-reviewed and published literature in the English language; the search dates were January 2006 to June 2018. There were 14 searches that mapped directly to the chapters and another 7 searches that helped provide context for various chapters. Search strategies are available on the obesity guideline webpage (http://obesitycanada.ca/guidelines/). Once a search was conducted, the results were uploaded to EndNote, where the duplicates were removed and the final set of citations was uploaded to DistillerSR software for selection and review. ${ }^{80}$ In addition to the electronic searches, the chapter authors identified additional citations and added them to the main search results.

Two reviewers completed screening of article titles and abstracts and independently selected studies for possible inclusion. Any citation that was selected for inclusion by either reviewer was moved to full-text review. One or more authors of 


\section{Box 3: Classification schemes ${ }^{77}$}

\section{Category of evidence}

- Level 1a: Evidence from meta-analysis of randomized controlled trials (RCTs)

- Level 1b: Evidence from at least 1 RCT

- Level 2a: Evidence from at least 1 controlled study without randomization

- Level 3: Evidence from nonexperimental descriptive studies, such as comparative studies, correlation studies and casecontrol studies

- Level 4: Evidence from expert committee reports or opinions or clinical experience of respected authorities, or both

\section{Strength of recommendation}

- Grade A: Directly based on level 1 evidence

- Grade B: Directly based on level 2 evidence or extrapolated recommendation from category 1 evidence

- Grade C: Directly based on level 3 evidence or extrapolated recommendation from level 1 or 2 evidence

- Grade D: Directly based on level 4 evidence or extrapolated recommendation from level 1, 2 or 3 evidence

Adapted with permission from BMJ Publishing Group Limited. Shekelle PG, Woolf SH, Eccles M, et al. Developing clinical guidelines. West J Med 1999;170:348-51.

the relevant chapter conducted reviews of full-text articles for relevancy. Selected citations were then assessed for their methodological quality using the Shekelle approach. ${ }^{77,81}$ Each citation was categorized into prevention, treatment, evaluation of diagnostic properties or prognosis. Once that selection was made, the appropriate methods worksheet was displayed in the DistillerSR platform, from which the methodological questions were answered and a level of evidence generated based on the type and quality of the study. The levels of evidence informed the strength of the recommendations and were generated from the methods worksheets (Box 3 ). ${ }^{77}$

\section{Development of recommendations}

Recommendations were formulated by the steering committee, chapter leads and chapter authors based on the highest level of evidence available (Box 3). ${ }^{77}$ Chapter leads and authors reviewed the type and strength of the available evidence (level) and added the study reference that provided the highest level of evidence for the specific recommendation.

Recognizing the importance of qualitative research in addressing questions pertinent to the care of people living with obesity, content experts in qualitative research (S.K., X.R.S., D.C.S., L.C., S.R.M.) were involved in the review of all materials informing these recommendations. Consensus appraisal of evidence quality by reviewers with expertise in qualitative methods informed the level of evidence in these recommendations.

Some grade D recommendations were formulated based on expert committee reports, opinions or clinical experience of respected authorities, and referenced accordingly; other grade D recommendations formulated by chapter authors were noted with "Consensus" after the grade D.
Table 3: Definitions of actionable verbs used in the recommendations $\mathbf{s}^{82-84}$

\section{Grade level}

Suggested terms

Level 1 , grade A recommendations

Level 2, grade B recommendations

Level 3 , grade $\mathrm{C}$ recommendations

Level 4 , grade $D$ and consensus recommendations

Use the term "should" Use the terms "may" or "can" Use the term "recommend" Use the term "suggest"

Chapter authors used a standardized terminology to make the recommendation more specific. The actionable verbs used for each of the recommendations were informed by the literature (Table 3). ${ }^{82-84}$

We used an iterative process to finalize the recommendations. Methodologists from MERST provided an independent review of recommendations that had a grade between $A$ and $C$, for which they examined the clarity of wording and the fidelity of the recommendations with the evidence. Two methodologists (a primary and secondary reviewer) reviewed each recommendation, using checklists as a guide for assigning levels of evidence to each citation. The methodologists met, discussed and reached consensus on grading the recommendations, and reported their suggestions regarding revisions to the wording or grading to the executive committee. Chapter leads edited the recommendations based on the MERST review process.

The executive committee voted on each recommendation, to ensure consensus. If a recommendation did not reach $100 \%$ agreement, the executive committee discussed the recommendation in depth until consensus was achieved. The chapter leads subsequently modified the wording of this recommendation, as required, and the executive committee approved the newly worded recommendation. The executive committee provided final approval of all the recommendations. All the recommendations included in this guideline achieved $100 \%$ agreement.

\section{External review}

External reviewers (primary care health care professionals and people living with obesity $[n=7])$ reviewed the recommendations for relevance and feasibility. We made some modifications to reflect language and the context of the primary care setting. A separate external peer review was conducted for each chapter.

\section{Management of competing interests}

Funding came from the Canadian Institutes of Health Research Strategic Patient-Oriented Research initiative, Obesity Canada's Fund for Obesity Collaboration and Unified Strategies (FOCUS) initiative, the Canadian Association of Bariatric Physicians and Surgeons, and in-kind support from the scientific and professional volunteers engaged in the process. The views of the funding body have not influenced the content of the guideline. All committee members (executive and steering committees), chapter leads and chapter authors were volunteers and not remunerated for their services. 
The executive committee developed and managed the competing interest policy and procedures for mitigating bias. The policy and disclosures of competing interest are available on the guideline website. All participants were required to disclose potential competing interests. We maintained detailed competing interest declarations throughout the process for all members of the steering and executive committees, as well as the participating methodologists from MERST. We used the International Committee of Medical Journal Editors' disclosure form, with the addition of government funding sources.

Individuals with relevant disclosures were not excluded from conducting the critical appraisals or voting on recommendations. However, the executive committee asked individuals with direct competing interests to abstain from voting in the areas in which they had the conflict. Any discussion regarding off-label use of drugs included the caveat that the use was off label.

As mentioned earlier, methodologists from MERST who had no competing interests reviewed and graded ${ }^{78}$ each included study to ensure the evidence had been appropriately assessed. They also reviewed the recommendations (graded between $\mathrm{A}$ and $\mathrm{C}$ ) to ensure that recommendations were aligned with the evidence. Finally, we conducted an external review process to assess the feasibility of the recommendations and evaluate for the presence of bias.

\section{Implementation}

Obesity Canada and the Canadian Association of Bariatric Surgeons and Physicians have created a joint guideline website (http://obesitycanada.ca/guidelines) that hosts the full guideline; interim updates; a quick reference guide; key messages; health care provider tools, slide kits, videos and webinars; and resources for people living with obesity and their support systems, in English and French. The guideline will be hosted on the website as a living document. Each chapter lead will monitor evidence related to this guideline and will collaborate with the executive committee to update the recommendations if new evidence becomes available that could influence the recommendations. A framework for implementation (5As Framework) is available in Appendix 2.

More than 10 years after the release of the first Canadian obesity guideline in 2006, access to obesity care remains an issue in Canada. ${ }^{37,71}$ Obesity is not officially recognized as a chronic disease by the federal, provincial and territorial, and municipal governments, despite declarations by the Canadian Medical Association $^{85}$ and the World Health Organization. ${ }^{86}$ The lack of recognition of obesity as a chronic disease by public and private payers, health systems, the public and media has a trickle-down effect on access to treatment. ${ }^{72}$ Obesity continues to be treated as a self-inflicted condition, which affects the type of interventions and approaches that are implemented by governments or covered by health benefit plans. ${ }^{87}$

Implementation of this guideline will require targeted policy action, as well as advocacy efforts and engagement from people living with obesity, their families and health care providers. Canadian organizations have come together to change the narrative regarding obesity in Canada, to eliminate weight bias and obesity stigma, and to change the way health care systems and policies approach obesity. ${ }^{88}$ This guideline will be used to assist in advocacy efforts to federal and provincial governments to improve the care of individuals with obesity.

\section{Other guidelines}

In 2006, the first evidence-based Canadian clinical practice guideline on the prevention and management of obesity in adults and children was released. ${ }^{43}$ In 2015, the Canadian Task Force on Preventive Health Care, in collaboration with scientific staff of the Public Health Agency of Canada and the McMaster Evidence Review and Synthesis Centre, released a set of recommendations for prevention of weight gain and use of behavioural and pharmacologic interventions to manage overweight and obesity in adults in primary care. ${ }^{89}$ This guideline was not designed to "apply to people with BMI of 40 or greater, who may benefit from specialized bariatric programs" and reviewed only intervention trials conducted in settings generalizable to Canadian primary care. The guideline also did not include surgical treatments.

\section{Gaps in knowledge}

The recommendations in this guideline are informed by the best level of evidence available in 2020. We acknowledge that ongoing research will continue to inform and advance obesity management. ${ }^{90,91}$

Current treatment options, apart from surgical intervention, rarely yield sustained weight loss beyond $20 \%$, and for some people living with obesity, this level of weight loss may be inadequate for the resolution or improvement of many adiposityrelated medical complications. There is a need for more treatment options to meet the needs of people with obesity. Weight regain continues to be a challenge for many patients who have received treatment. ${ }^{92}$

\section{Conclusion}

Obesity is a prevalent, complex chronic disease that affects a large number of adults in Canada and globally, and yet only a small fraction of people living with obesity who could benefit from treatment have access to care. This updated evidenceinformed guideline is an attempt to enhance access and care by people living with obesity through recognition among health care providers that obesity requires long-term treatment. The newer insights into appetite regulation and the pathophysiology of obesity have opened new avenues for treating this chronic disease. Reducing weight bias and stigma, understanding the root causes of obesity, and promoting and supporting patient-centred behavioural interventions and appropriate treatment by health care providers - preferably with the support of interdisciplinary care teams - will raise the standards of care and improve the well-being of people living with obesity. Dissemination and implementation of this guideline are integral components of our goals to address this prevalent chronic disease. Much more effort is needed to close the gaps in knowledge through obesity research, education, prevention and treatment. 


\section{References}

1. Prospective Studies Collaboration; Whitlock G, Lewington S, Sherliker P, et al. Body-mass index and cause-specific mortality in 900000 adults: collaborative analyses of 57 prospective studies. Lancet 2009;373:1083-96.

2. Global BMI Mortality Collaboration; Di Angelantonio E, Bhupathiraju ShN, Wormser $D$, et al. Body-mass index and all-cause mortality: Individual-participant-data meta-analysis of 239 prospective studies in four continents. Lancet 2016;388: 776-86.

3. Abdullah A, Peeters A, de Courten M, et al. The magnitude of association between overweight and obesity and the risk of diabetes: a meta-analysis of prospective cohort studies. Diabetes Res Clin Pract 2010;89:309-19.

4. Aune D, Norat T, Vatten LJ. Body mass index, abdominal fatness and the risk of gallbladder disease. Eur J Epidemiol 2015;30:1009-19.

5. Longo M, Zatterale F, Naderi J, et al. Adipose tissue dysfunction as determinant of obesity-associated metabolic complications. Int J Mol Sci 2019;20: E2358.

6. Aune D, Norat T, Vatten LJ. Body mass index and the risk of gout: A systematic review and dose-response meta-analysis of prospective studies. Eur J Nutr 2014;53:1591-601.

7. Fontaine KR, Redden DT, Wang C, et al. Years of life lost due to obesity. JAMA 2003;289:187-93.

8. Grover SA, Kaouache M, Rempel P, et al. Years of life lost and healthy life-years lost from diabetes and cardiovascular disease in overweight and obese people: a modelling study. Lancet Diabetes Endocrinol 2015;3:114-22.

9. Wolin KY, Carson K, Colditz GA. Obesity and cancer. Oncologist 2010;15:556-65.

10. Ackerman SE, Blackburn OA, Marchildon F, et al. Insights into the link between obesity and cancer. Curr Obes Rep 2017;6:195-203.

11. Sharma AM. M, M, M \& M: a mnemonic for assessing obesity. Obes Rev 2010;11: 808-9.

12. NCD Risk Factor Collaboration (NCD-RisC). Worldwide trends in body-mass index, underweight, overweight, and obesity from 1975 to 2016: a pooled analysis of 2416 population-based measurement studies in 128.9 million children, adolescents, and adults. Lancet 2017;390:2627-42.

13. Obesity in Canada - Snapshot. Ottawa: Public Health Agency of Canada; 2009. Available: www.canada.ca/en/public-health/services/reports-publications/ obesity-canada-snapshot.html (accessed 2020 May 22).

14. Obesity in Canada - Health and economic implications. Ottawa: Public Health Agency of Canada; modified 2011 June 23. Available: www.canada.ca/en /public-health/services/health-promotion/healthy-living/obesity-canada/health -economic-implications.html (accessed 2020 May 22).

15. Anis AH, Zhang W, Bansback N, et al. Obesity and overweight in Canada: an updated cost-of-illness study. Obes Rev 2010;11:31-40.

16. Guh DP, Zhang W, Bansback N, et al. The incidence of co-morbidities related to obesity and overweight: a systematic review and meta-analysis. BMC Public Health 2009;9:88.

17. Sutin AR, Stephan Y, Terracciano A. Weight discrimination and risk of mortality. Psychol Sci 2015;26:1803-11

18. Mechanick JI, Hurley DL, Garvey WT. Adiposity-based chronic disease as a new diagnostic term: the American Association of Clinical Endocrinologists and American College Of Endocrinology position statement. Endocr Pract 2017;23: $372-8$.

19. Garvey WT, Mechanick JI. Proposal for a scientifically correct and medically actionable disease classification system (ICD) for obesity. Obesity (Silver Spring) 2020;28:484-92

20. Cedernaes J, Huang W, Ramsey KM, et al. Transcriptional basis for rhythmic control of hunger and metabolism within the AgRP neuron. Cell Metab 2019;29: 1078-91.e5.

21. Fasshauer M, Blüher M. Adipokines in health and disease. Trends Pharmacol Sci 2015;36:461-70.

22. Secher A, Jelsing J, Baquero AF, et al. The arcuate nucleus mediates GLP-1 receptor agonist liraglutide-dependent weight loss. J Clin Invest 2014;124: 4473-88.
23. Sternson SM, Eiselt A-K. Three pillars for the neural control of appetite. Annu Rev Physiol 2017;79:401-23.

24. Hill JO. Understanding and addressing the epidemic of obesity: an energy balance perspective. Endocr Rev 2006;27:750-61.

25. Mebel DM, Wong JC, Dong YJ, et al. Insulin in the ventral tegmental area reduces hedonic feeding and suppresses dopamine concentration via increased reuptake. Eur J Neurosci 2012;36:2336-46.

26. Bliss ES, Whiteside E. The gut-brain axis, the human gut microbiota and their integration in the development of obesity. Front Physiol 2018;9:900.

27. van Bloemendaal L, Veltman DJ, Ten Kulve JS, et al. Brain reward-system activation in response to anticipation and consumption of palatable food is altered by glucagon-like peptide-1 receptor activation in humans. Diabetes Obes Metab 2015;17:878-86.

28. Sharma AM, Kushner RF. A proposed clinical staging system for obesity. Int J Obes (Lond) 2009;33:289-95.

29. Grundy SM, Neeland IJ, Turer AT, et al. Waist circumference as measure of abdominal fat compartments. J Obes 2013;2013:454285.

30. Ross R, Neeland IJ, Yamashita S, et al. Waist circumference as a vital sign in clinical practice: a Consensus Statement from the IAS and ICCR Working Group on Visceral Obesity. Nat Rev Endocrinol 2020;16:177-89.

31. Neeland IJ, Ross R, Després J-P, et al.; International Atherosclerosis Society; International Chair on Cardiometabolic Risk Working Group on Visceral Obesity. Visceral and ectopic fat, atherosclerosis, and cardiometabolic disease: a position statement. Lancet Diabetes Endocrinol 2019;7:715-25.

32. Hruby A, Hu FB. The epidemiology of obesity: a big picture. Pharmacoeconomics 2015;33:673-89.

33. Padwal RS, Pajewski NM, Allison DB, et al. Using the Edmonton obesity staging system to predict mortality in a population-representative cohort of people with overweight and obesity. CMAJ 2011;183:E1059-66.

34. Canning KL, Brown RE, Wharton S, et al. Edmonton Obesity Staging System prevalence and association with weight loss in a publicly funded referralbased obesity clinic. J Obes 2015;2015:619734.

35. Kuk JL, Ardern Cl, Church TS, et al. Edmonton Obesity Staging System: association with weight history and mortality risk. Appl Physiol Nutr Metab 2011;36: 570-6.

36. Ogunleye A, Osunlana A, Asselin J, et al. The 5As team intervention: bridging the knowledge gap in obesity management among primary care practitioners [published erratum in BMC Res Notes 2016;9:164]. BMC Res Notes 2015;8:810.

37. Report card on access to obesity treatment for adults in Canada 2017. Edmonton: Obesity Canada; 2017.

38. Block JP, DeSalvo KB, Fisher WP. Are physicians equipped to address the obesity epidemic? Knowledge and attitudes of internal medicine residents. Prev Med 2003;36:669-75.

39. Janke EA, Ramirez ML, Haltzman B, et al. Patient's experience with comorbidity management in primary care: a qualitative study of comorbid pain and obesity. Prim Health Care Res Dev 2016;17:33-41.

40. Greener J, Douglas F, van Teijlingen E. More of the same? Conflicting perspectives of obesity causation and intervention amongst overweight people, health professionals and policy makers. Soc Sci Med 2010;70:1042-9.

41. Kirk SFL, Price SL, Penney TL, et al. Blame, shame, and lack of support: a multilevel study on obesity management. Qual Health Res 2014;24:790-800.

42. Alberga AS, Edache IY, Forhan M, et al. Weight bias and health care utilization: a scoping review. Prim Health Care Res Dev 2019;20:e116. doi: 10.1017/S1463423619000227.

43. Lau DCW, Douketis JD, Morrison KM, et al.; Obesity Canada Clinical Practice Guidelines Expert Panel. 2006 Canadian clinical practice guidelines on the management and prevention of obesity in adults and children [summary]. CMAJ 2007;176(Suppl):S1-13.

44. Obesity and overweight. Geneva: World Health Organization; 2020. Available: www.who.int/news-room/fact-sheets/detail/obesity-and-overweight (accessed 2020 May 22).

45. Table 13-10-0096-20: Body mass index, overweight or obese, self-reported, adult, age groups (18 years and older). Ottawa: Statistics Canada. 
46. Twells LK, Gregory DM, Reddigan J, et al. Current and predicted prevalence of obesity in Canada: a trend analysis. CMAJ Open 2014;2:E18-26.

47. Hall KD, Heymsfield SB, Kemnitz JW, et al. Energy balance and its components: implications for body weight regulation. Am J Clin Nutr 2012;95:989-94.

48. Lee M, Ata RN, Brannick MT. Malleability of weight-biased attitudes and beliefs: a meta-analysis of weight bias reduction interventions. Body Image 2014;11:251-9.

49. Project Implicit. 2011. Available: https://implicit.harvard.edu/implicit/ (accessed 2020 May 22).

50. Luig T, Anderson R, Sharma AM, et al. Personalizing obesity assessment and care planning in primary care: patient experience and health outcomes in everyday life and health. Clin Obes 2018;8:411-23.

51. Vallis M, Piccinini-Vallis H, Sharma AM, et al. Clinical review: modified 5 As: minimal intervention for obesity counseling in primary care. Can Fam Physician 2013; 59:27-31.

52. Sharma AM, Campbell-Scherer D. Redefining obesity: beyond the numbers. Obesity (Silver Spring) 2017;25:660-1.

53. Camhi SM, Bray GA, Bouchard C, et al. The relationship of waist circumference and BMI to visceral, subcutaneous, and total body fat: sex and race differences. Obesity (Silver Spring) 2011;19:402-8.

54. Mabire L, Mani R, Liu L, et al. The influence of age, sex and body mass index on the effectiveness of brisk walking for obesity management in adults: a systematic review and meta-analysis. J Phys Act Health 2017;14:389-407.

55. Raynor HA, Davidson PG, Burns H, et al. Medical nutrition therapy and weight loss questions for the evidence analysis library prevention of type 2 diabetes project: systematic reviews. J Acad Nutr Diet 2017;117:1578-611.

56. Raynor HA, Champagne CM. Position of the Academy of Nutrition and Dietetics: interventions for the treatment of overweight and obesity in adults. J Acad Nutr Diet 2016;116:129-47.

57. Sumithran P, Prendergast LA, Delbridge E, et al. Long-term persistence of hormonal adaptations to weight loss. N Engl J Med 2011;365:1597-604.

58. Rosenbaum M, Hirsch J, Gallagher DA, et al. Long-term persistence of adaptive thermogenesis in subjects who have maintained a reduced body weight. Am J Clin Nutr 2008;88:906-12.

59. Koliaki C, Spinos T, Spinou M, et al. Defining the optimal dietary approach for safe, effective and sustainable weight loss in overweight and obese adults. Healthcare (Basel) 2018;6:E73.

60. Look AHEAD Research Group. Eight-year weight losses with an intensive lifestyle intervention: the look AHEAD study. Obesity (Silver Spring) 2014;22:5-13.

61. Vallis M. Are behavioural interventions doomed to fail? Challenges to selfmanagement support in chronic Diseases. Can J Diabetes 2015;39:330-4.

62. Wadden TA, Hollander P, Klein S, et al.; NN8022-1923 Investigators. Weight maintenance and additional weight loss with liraglutide after low-calorie-dietinduced weight loss: the SCALE Maintenance randomized study. Int J Obes (Lond) 2013;37:1443-51.

63. Greenway FL, Fujioka K, Plodkowski RA, et al.; COR-I Study Group. Effect of naltrexone plus bupropion on weight loss in overweight and obese adults (COR-I): a multicentre, randomised, double-blind, placebo-controlled, phase 3 trial. Lancet 2010;376:595-605.

64. Pi-Sunyer X, Astrup A, Fujioka K, et al.; SCALE Obesity and Prediabetes NN80221839 Study Group. A randomized, controlled trial of $3.0 \mathrm{mg}$ of liraglutide in weight management. N Engl J Med 2015;373:11-22.

65. Richelsen B, Tonstad S, Rossner S, et al. Effect of orlistat on weight regain and cardiovascular risk factors following a very-low-energy diet in abdominally obese patients:a 3-year randomized, placebo-controlled study. Diabetes Care 2007;30:27-32.

66. Rucker D, Padwal R, Li SK, et al. Long term pharmacotherapy for obesity and overweight: updated meta-analysis [published erratum in BMJ 2007;335:0-a]. BMJ 2007;335:1194-9.

67. American Association of Diabetes Educators. Addressing obesity via diabetes self-management education and training. Diabetes Educ 2012;38:151-4.

68. Kaly P, Orellana S, Torrella $\mathrm{T}$, et al. Unrealistic weight loss expectations in candidates for bariatric surgery. Surg Obes Relat Dis 2008;4:6-10.
69. Sharma M. Behavioural interventions for preventing and treating obesity in adults. Obes Rev 2007;8:441-9.

70. Byrne NM, Meerkin JD, Laukkanen R, et al. Weight loss strategies for obese adults: personalized weight management program vs. standard care. Obesity (Silver Spring) 2006;14:1777-88

71. Report card on access to obesity treatment for adults in Canada 2019. Edmonton: Obesity Canada; 2019.

72. Sharma AM, Ramos Salas X. Obesity prevention and management strategies in Canada: shifting paradigms and putting people first. Curr Obes Rep 2018;7:89-96.

73. Forhan M, Ramos Salas X. Inequities in healthcare: a review of bias and discrimination in obesity treatment. Can J Diabetes 2013;37:205-9.

74. Dietz WH, Baur LA, Hall K, et al. Management of obesity: improvement of healthcare training and systems for prevention and care. Lancet 2015;385:2521-33.

75. Sharma AM. Inequalities in access to bariatric surgery in Canada. CMAJ 2016;188:317-8.

76. Freedhoff $Y$, Sharma AM. "Lose 40 pounds in 4 weeks": regulating commercial weight-loss programs. CMAJ 2009;180:367-8.

77. Shekelle PG, Woolf SH, Eccles M, et al. Developing clinical guidelines. West J Med 1999;170:348-51.

78. Brouwers MC, Kho ME, Browman GP, et al.; AGREE Next Steps Consortium. AGREE II: advancing guideline development, reporting and evaluation in health care. CMAJ 2010;182:E839-42

79. Crandall B, Klein G, Hoffman RR. Working minds: a practitioner's guide to cognitive task analysis. Cambridge (MA): MIT Press; 2006.

80. DistillerSR enterprise plan. Ottawa: Evidence Partners: Available: www. evidencepartners.com/products/distillersr-systematic-review-software/ (accessed 2020 May 22).

81. Shekelle P, Woolf S, Grimshaw JM, et al. Developing clinical practice guidelines: reviewing, reporting, and publishing guidelines; updating guidelines; and the emerging issues of enhancing guideline implementability and accounting for comorbid conditions in guideline development. Implement Sci 2012;7:62.

82. Guyatt GH, Cooke DJ, Jaeschke R, et al. Grades of recommendation for antithrombotic agents: American College of Chest Physicians Evidence-Based Clinical Practice Guidelines (8th Edition). Chest 2008;133(Suppl):123S-31S.

83. Badesch DB, Abman SH, Simonneau G, et al. Medical therapy for pulmonary arterial hypertension: updated ACCP evidence-based clinical practice guidelines. Chest 2007;131:1917-28.

84. Rosenfeld RM, Shiffman RN. Clinical practice guideline development manual: a quality-driven approach for translating evidence into action. Otolaryngol Head Neck Surg 2009;140(Suppl 1):S1-43.

85. Obesity as a chronic medical disease [policy]. Ottawa: Canadian Medical Association; 2015, reviewed 2019 Mar. 3. Available: https://policybase.cma.ca/en/ permalink/policy11700 (accessed 2020 May 22).

86. Obesity: preventing and managing the global epidemic - Report of a WHO Consultation (WHO Technical Report Series 894). Geneva: World Health Organization; 2000.

87. Ramos Salas X, Forhan M, Caulfield T, et al. A critical analysis of obesity prevention policies and strategies. Can J Public Health 2018;108:e598-608.

88. Canadian Obesity Advocacy Network (COAN). Edmonton: Obesity Canada. Available: https://obesitycanada.ca/coan (accessed 2020 May 22).

89. Brauer P, Gorber SC, Shaw E; Canadian Task Force on Preventive Health Care. Recommendations for prevention of weight gain and use of behavioural and pharmacologic interventions to manage overweight and obesity in adults in primary care. CMAJ 2015;187:184-95.

90. Jastreboff AM, Kotz CM, Kahan S, et al. Obesity as a disease: the Obesity Society 2018 position statement. Obesity (Silver Spring) 2019;27:7-9.

91. Park B-y, Byeon K, Lee MJ, et al. The orbitofrontal cortex functionally links obesity and white matter hyperintensities. Sci Rep 2020;10:2930.

92. Look AHEAD Research Group; Wing RR, Bolin P, Brancati FL, et al. Cardiovascular effects of intensive lifestyle intervention in type 2 diabetes. $N$ Engl J Med 2013;369:145-54. 
Competing interests: Sean Wharton reports receiving honoraria and travel expenses and has participated in academic advisory boards for Novo Nordisk, Bausch Health, Eli Lilly and Janssen. Sean Wharton is also the medical director of a medical clinic specializing in weight management and diabetes. David Lau reports receiving grants and research support from AstraZeneca, Novo Nordisk and the Canadian Institutes of Health Research (ClHR); speaker bureau fees from AstraZeneca, Bausch Health, Boehringer Ingelheim, Diabetes Canada, Eli Lilly, Merck and Novo Nordisk; and consulting fees from Amgen, AstraZeneca, Bausch Health, Boehringer Ingelheim, Gilead, HLS Therapeutics, Janssen, Eli Lilly and Novo Nordisk. Michael Vallis is a member of advisory boards for Novo Nordisk, Bausch Health and LifeScan. Michael Vallis has also received consulting fees from Bausch Health, LifeScan, Novo Nordisk and Sanofi, and speaking fees from Novo Nordisk, Sanofi, Bausch Health, Abbott and AbbVie. Arya Sharma reports receiving speaker's bureau and consulting fees from Novo Nordisk, Bausch Pharmaceuticals and AstraZeneca. Laurent Biertho reports receiving grants from Johnson and Johnson and Medtronic, and is a member of advisory boards for Novo Nordisk and Bausch Health, outside the submitted work. Denise Campbell-Scherer has no personal financial relationships, but reports receiving research funding from the following sources in the past 3 years: Novo Nordisk Alberta Diabetes Fund (NOVAD), a peer-reviewed grant that is a partnership between the University Hospital Foundation, Novo Nordisk and Alberta Innovates joint funders; Alberta Innovates Health Solutions (Cancer Prevention Research Opportunity and Collaborative Research and Innovation Opportunities competitions), CIHR (Strategy for Patient-Oriented Research and Knowledge-to-Action competitions); Northern Alberta Family Medicine Fund; and the Alberta Cancer Prevention and Legacy Fund. She also reports receiving knowledge transfer funding from the following sources in the past 3 years: an unrestricted education grant from Obesity Canada, funded by Novo Nordisk Global; a Worldwide University Network Meeting Grant; an Agency for Healthcare Research and Quality R13 grant for a Healthcare Effectiveness and Outcomes Research; and a Physician Learning Program grant from Alberta Health and the Alberta Medical Association. Angela Alberga reports receiving the following grants: the Santé Award from Fonds de Recherche du Quebec, the Mitacs Accelerate Grant, and the Concordia University Start-up Team Grant, outside the submitted work. Jennifer Brown reports receiving nonfinancial support from Novo Nordisk, and personal fees from Bausch Health, Dietitians of Canada, Obesity Canada and the Canadian Association of Bariatric Physicians \& Surgeons. Yoni Freedhoff is the co-owner of the Bariatric Medical Institute and Constant Health, which provide weight management services; Constant Health has received a grant from Novo Nordisk. Yoni Freedhoff is also the author of The Diet Fix: Why Diets Fail and How to Make Yours Work published by Crown Publishing Group, and receives royalties for the book. In addition, he is the sole author of the Weighty Matters blog and a column for Medscape and many other op-eds and articles in which he has publicly expressed opinions about the treatment, management and prevention of obesity. Yoni Freedhoff also regularly speaks on topics related to obesity and receives honoraria and travel costs and expenses for same. Michel Gagner reports receiving speaker honoraria from Ethicon, WL Gore and Medtronic; consulting fees from Novo Nordisk, Bausch Health and Lexington Medical; and holds stock options with Lexington Medical. Margaret Hahn reports receiving consulting fees from Alkermes. Marie-France Langlois reports receiving personal fees from Novo Nordisk, Valeant, Merck Canada, Sanofi, Eli Lilly and Boehringer Ingelheim; a grant from Merck Canada; and other fees from AstraZeneca and from TIMI (Thrombolysis in Myocardial Infarction) Study Group for diabetes clinical research as a principal investigator, all outside the submitted work. David Macklin reports receiving personal fees from Novo Nordisk and Bausch Health, outside the submitted work. Priya Manjoo reports receiving personal fees from Novo Nordisk, Bausch Health and Sanofi; and grants from Boehringer Ingelheim, Sanofi and AstraZeneca, outside the submitted work. Marie-Philippe Morin reports receiving speaker honoraria from Novo Nordisk, Bausch Health, Eli Lilly, Boehringer Ingelheim, Nestlé Health Science, Janssen and AstraZeneca; research subvention from Novo Nordisk and Sanofi; and consultation honoraria from Novo Nordisk, Bausch Health, Eli Lilly, Boehringer Ingelheim, Janssen and AstraZeneca. Sue Pedersen reports receiving personal fees from Novo Nordisk, Bausch Health, Janssen, Eli Lilly, Merck, AstraZeneca, Boehringer Ingelheim, Sanofi, Pfizer; grants from Eli Lilly, AstraZeneca, Boehringer Ingelheim and Sanofi; and nonfinancial support from Novo Nordisk, Bausch Health, Janssen, Eli Lilly, AstraZeneca, Boehringer Ingelheim and Sanofi, outside the submitted work. Megha Poddar reports receiving honoraria for continuing medical education (CME) from Novo Nordisk, Bausch Health, Boehringer Ingelheim, Eli Lilly, Jenssen, Merck, the Canadian Collaborative Research Network and the Antibody Network; education grants from Novo Nordisk and Bausch Health; fees for mentorship from Novo Nordisk; fees for membership of advisory boards from Novo Nordisk and Bausch Health; and a quality improvement project grant from Boehringer Ingelheim. Paul Poirier reports receiving fees for consulting and continuing medical education from AstraZeneca, Boehringer Ingelheim, Janssen, Eli Lilly, Novo Nordisk, Valeant and Bausch Health, outside the submitted work. Judy Shiau reports receiving personal fees from Novo Nordisk and Bausch Health, outside the submitted work. Diana Sherifali reports receiving consulting fees for advice regarding chronic disease and diabetes management from Merck, and a grant from Obesity Canada to support the literature review process, during the conduct of the study. John Sievenpiper reports receiving grants from CIHR, the Nutrition Trialists Fund at the University of Toronto, the International Nut and Dried Fruit Council Foundation, the Tate \& Lyle Nutritional Research Fund at the University of Toronto, the American Society for Nutrition, the Glycemic Control and Cardiovascular Disease in Type 2 Diabetes Fund at the University of Toronto, the National Dried Fruit Trade Association, PSI Graham Farquharson Knowledge Translation Fellowship, the Diabetes Canada Clinician Scientist award, the Banting \& Best Diabetes Centre Sun Life Financial New Investigator Award, the Canada Foundation for Innovation, and the Ministry of Research and Innovation's Ontario Research Fund. Dr. Sievenpiper has received personal fees from Perkins Coie LLP, Tate \& Lyle, Dairy Farmers of Canada, PepsiCo, FoodMinds LLC, European Fruit Juice Association, International Sweeteners Association, Nestlé Health Science, Canadian Society for Endocrinology and Metabolism, GI Foundation, Pulse Canada, Wirtschaftliche Vereinigung Zucker e.V., Abbott, Biofortis, the European Food Safety Authority, the Physicians Committee for Responsible Medicine, the Soy Nutrition Institute and the Comité Européen des Fabricants de Sucre. Dr. Sievenpiper has received nonfinancial support from Tate \& Lyle, PepsiCo, FoodMinds LLC, European Fruit Juice Association, International Sweeteners Association, Nestlé Health Science, Wirtschaftliche Vereinigung Zucker e.V., Abbott, Biofortis, the European Food Safety Authority and the Physicians Committee for Responsible Medicine, Kellogg Canada, American Peanut Council, Barilla, Unilever, Unico Primo, Loblaw Companies, WhiteWave Foods, Quaker, California Walnut Commission, Almond Board of California, outside the submitted work. Dr. Sievenpiper is a member of the International Carbohydrate Quality Consortium and the Clinical Practice Guidelines Expert Committees of Diabetes Canada, European Association for the Study of Diabetes, Canadian Cardiovascular Society, and Obesity Canada, and holds appointments as an Executive Board Member of the Diabetes and Nutrition Study Group of the European Association for the Study of Diabetes, and as Director of the Toronto 3D Knowledge Synthesis and Clinical Trials Foundation. He is also an unpaid scientific adviser for the Program in Food Safety, Nutrition and Regulatory Affairs and the Carbohydrates Committee of the International Life Science Institute North America. He has a spousal relationship with an employee of Anheuser-Busch InBev. Sanjeev Sockalingam reports receiving honoraria from Bausch Health Canada within the last 36 months. Valerie Taylor reports receiving speaker fees from Sunovion. Shahebina Walji reports receiving consulting 
or advisory board fees from Novo Nordisk, Bausch Health and Takeda and speaker's bureau fees from Novo Nordisk and Bausch Health. Shahebina Walji also reports selling Optifast Meal replacements through a weight management centre Optifast is a product produced and sold by Nestlé. No other competing interests were declared.

This article has been peer reviewed.

Affiliations: Departments of Medicine (Wharton), Endocrinology and Metabolism (Poddar, Sherifali), Family Medicine (Naji, Tytus) and Health Research Methods, Evidence and Impact Canada (Naji), McMaster University, Hamilton, Ont; The Wharton Medical Clinic (Wharton, Poddar), Hamilton, Ont.; Departments of Medicine (Lau, Nerenberg) and Family Medicine (Boyling, Henderson, McInnes, Walji, Wicklum), Cumming School of Medicine, University of Calgary, Calgary, Alta.; Julia McFarlane Diabetes Research Centre and Libin Cardiovascular Institute of Alberta (Lau), Calgary, Alta.; Department of Family Medicine (Vallis, PiccininiVallis), Dalhousie University, Halifax, NS; Departments of Medicine (Sharma, Toth), Family Medicine (Campbell-Scherer, Kemp), Agricultural, Food and Nutritional Science (Bell, Pereira), Physical Education and Recreation (Boulé), and Occupational Therapy (Forhan), University of Alberta, Edmonton, Alta.; Adult Bariatric Specialty Clinic (Sharma), Royal Alexandra Hospital, Edmonton, Alta.; Obesity Canada (Sharma, Patton, Ramos Salas), Edmonton, Alta.; Department of Surgery (Biertho), Laval University, Quebec, Que.; School of Human Kinetics (Adamo, Prud'homme), University of Ottawa, Ottawa, Ont.; Department of Health, Kinesiology \& Applied Physiology (Alberga), Concordia University, Montréal, Que.; Bariatric Centre of Excellence (Brown), The Ottawa Hospital, Ottawa, Ont.; Departments of Family Practice (Calam) and Endocrinology (Manjoo), University of British Columbia, Vancouver, BC; UBC Family Practice Residency Program (Calam) and Pfizer/Heart and Stroke Foundation Chair in Cardiovascular Prevention Research (Lear), St. Paul's Hospital, Vancouver, BC; nutrition consultant (Clarke), Hamilton, Ont.; Indigenous Health Dialogue (Crowshoe), Health Sciences Centre, University of Calgary, Calgary, Alta.; Main East Medical Associates (Divalentino), Hamilton, Ont.; Bariatric Medical Institute (Freedhoff), Ottawa, Ont.; Department of Family Medicine (Freedhoff) and Division of Endocrinology and Metabolism (Shiau), Department of Medicine, University of Ottawa, Ottawa, Ont.; Herbert Wertheim School of Medicine (Gagner), Florida International University, Miami, Fla.; Hôpital du Sacre Coeur de Montréal (Gagner), Montréal, Que.; Humber River Hospital (Glazer), Toronto, Ont.; Division of Endocrinology and Metabolism (Glazer), Queen's University, Kingston, Ont.; Departments of Internal Medicine (Glazer), Psychiatry (Hawa, Sockalingam), Family and Community Medicine (Macklin) and Nutritional Sciences (Sievenpiper), University of Toronto, Toronto, Ont.; Alberta Health Services (Grand, Hung, Johnson-Stoklossa), Edmonton, Alta.; Departments of Family Medicine and Public Health Sciences and Policy Studies (Green), Queen's University, Kingston, Ont.; Kingston Health Sciences Centre (Green), Kingston, Ont.; Providence Care Hospital (Green), Kingston, Ont.; Centre for Addiction and Mental Health (Hahn, Sockalingam), Toronto, Ont.; University Health Network (Hawa, Sockalingam), Toronto, Ont.; Division of General Surgery (Hong), McMaster University, Hamilton, Ont.; Department of Family Medicine and Biobehavioral Health (Jacklin), University of Minnesota Medical School Duluth Campus, Duluth, Minn.; School of Kinesiology and Health Studies (Janssen), Queen's University, Kingston, Ont.; School of Health and Human Performance (Kirk), Dalhousie University, Halifax, NS; School of Kinesiology and Health Science (Wharton, Kuk), York University, Toronto, Ont.; Divi- sion of Endocrinology (Langlois), Université de Sherbrooke, Sherbrooke, Que.; Centre intégré universitaire de santé et de services sociaux de l'Estrie - Centre hospitalier universitaire de Sherbrooke (Langlois), Sherbrooke, Que.; School of Kinesiology (Lear), Simon Fraser University, Vancouver, BC; Medcan Clinic (Macklin), Toronto, Ont.; Cardiometabolic Collaborative Clinic (Manjoo), Vancouver Island Health Authority, Victoria, BC; Institut universitaire de cardiologie et de pneumologie de Québec (Morin, Poirier), Laval University, Québec, Que.; Foothills Medical Centre (Nerenberg), Calgary, Alta.; C-ENDO Diabetes \& Endocrinology Clinic (Pedersen), Calgary, Alta.; LMC Diabetes and Endocrinology (Poddar), Toronto, Ont.; Department of Medicine (Rueda-Clausen), University of Saskatchewan, Regina, Sask.; Regina General Hospital (RuedaClausen), Regina, Sask.; Education Psychology (Russell-Mayhew), Werklund School of Education, University of Calgary, Calgary, Alta.; LEAF Weight Management Clinic (Shiau), Ottawa, Ont.; Heather M. Arthur Population Health Research Institute/Hamilton Health Sciences Chair in Interprofessional Health Research, School of Nursing (Sherifali), McMaster University, Hamilton, Ont.; Division of Endocrinology \& Metabolism (Sievenpiper), St. Michael's Hospital, Toronto, Ont.; Department of Psychiatry (Taylor), University of Calgary, Calgary, Alta.; School of Pharmacy (Twells), Memorial University, St. John's, NL; Steelcity Medical Clinic (Tytus), Hamilton, Ont.; Calgary Weight Management Centre (Walji), Calgary, Alta.; School of Population and Public Health (Walker), University of British Columbia, Vancouver, BC; Centre for Excellence in Indigenous Health (Walker), University of British Columbia, Vancouver, BC.; O'Brien Institute of Public Health (Wicklum), University of Calgary, Calgary, Alta.

Contributors: All of the authors contributed to the conception and design of the work and the acquisition, analysis, and interpretation of data. All of the authors drafted the manuscript, revised it critically for important intellectual content, gave final approval of the version to be published and agreed to be accountable for all aspects of the work.

Funding: Funding for this initiative was provided by Obesity Canada, the Canadian Association of Bariatric Physicians and Surgeons, and the Canadian Institutes of Health Research through a Strategy for PatientOriented Research grant, with no participants or authors receiving any personal funding for their creation.

Acknowledgements: The authors thank Obesity Canada staff members Dawn Hatanaka, Nicole Pearce, Brad Hussey, Robert Fullerton and Patti Whitefoot-Bobier for their coordinating support as well as their contributions for the development of the Obesity Guidelines website, online resources, tables and figures. The authors also thank members of the Obesity Canada Public Engagement Committee (Lisa Schaffer, Candace Vilhan, Kelly Moen, Doug Earle, Brenndon Goodman), who contributed to the creation of the research questions and reviewed key messages for individuals living with obesity and recommendations for health care providers. The authors also thank McMaster Evidence Review and Synthesis Team (MERST) member Donna Fitzpatrick, who played a critical role in developing the methods needed for the guideline; and thank the reviewers whose comments helped to improve the chapters and this manuscript. The authors thank Barbara Kermode-Scott and Brad Hussey for editing the guidelines, Elham Kamran and Rubin Pooni for research assistance, and Jordan Tate from the Physician Learning Program at the University of Alberta for designing the 5As framework for the guideline.

Correspondence to: Sean Wharton, sean.wharton@utoronto.ca 